\title{
Patterns of Artificial Sweetener Use and Weight . Change in an American Cancer Society Prospective Study
}

\author{
STEVEN D. STELLMAN and LAWRENCE GARFINKEL \\ American Cancer Society, New York
}

\begin{abstract}
Extreme obesity and leanness are risk factors for many types of cancer. An earlier American Cancer Society study (1959-1972) found a nearly twofold increased risk for death from all causes in men and women who weighed $40 \%$ or more above average for their age and heighit, and found elevated cancer rates as well. $A$ new (1982), ongoing ACS prospective study of 1.2 million men and women continues to find increased death rates from all causes and from cancer in the very heavy and the very lean.

Artificial sweetener (AS) use is an important correlate of relative weight in this population. The relationship between weight change during the year preceding enrolment and AS usage was studied in a highly homogeneous subgroup of 78694 women ages $50-69$ years. The percentage of users increased with body mass index (BMI) and was inversely related to age. Users were significantly more likely than non-users to gain weight, regardless of initial BMI. Among those who gained weight, the average number of lbs gained by AS users was higher (by $0.5-1.5 \mathrm{lb}$ ) than the amount gained by non-users.

Within the entire cohort, AS users of both sexes ate chicken, fish and vegetables significantly more often than did non-users and consumed beef, butter, white bread, potatoes, ice cream and chocolate significantly less often, suggesting that our weight change results are not explicable by differences in food consumption patterns.
\end{abstract}

Previous American Cancer Society studies have found relative weight to be a risk factor for death from cancer and other causes. In a prospective study of over 1 million men and women conducted in 1959-1972, relative risks for total mortality ranged from 1.25 in men $20 \%$ or more underweight, to 1.87 in men $40 \%$ or more overweight $(R R=1.00$ for average weight for a given sex, age and height). In women the corresponding mortality ratios were 1.19 for $20 \%$ or more underweight and 1.89 for $40 \%$ or more overweight. Colon-rectum cancer and prostate cancer death rates were higher in overweight men, and death rates from cancer of the endometrium, cervix, gall bladder, ovary and breast were elevated in obese women (Lew \& Garfinkel, 1979).

In 1982 the ACS began a new prospective study, details of which have previously been reported (Stellman \& Garfinkel, 1986a). More than 77000 ACS volunteer 'researchers' enrolled over 1.2 million men and women in a long-term prospective study. Those enrolled, who were usually friends, neighbors, or relatives of the volunteers, completed a four-page confidential questionnaire on history of cancer and other diseases; occupational exposures; use of medicines and vitamins; menstrual and

Address reprint requests to: S. D. Stellman, Biostatistics and Epidemiologic Research, New York City Dept. of Health, 125 Worth St., Room 316, New York, NY 10013,.U.S.A. 
reproductive history; diet and drinking habits; and numerous other habits, including smoking. Enrolment was by family groups with at least one person in the household 45 years of age or older. All members of the household over 30 years of age were asked to complete a questionnaire.

Enrolment of subjects was carried out in all 50 states, the District of Columbia, and Puerto Rico. It began in September 1982 and was essentially completed by the end of November 1982. Every second year, the researchers are sent a list of the persons enrolled and asked to check whether those enrolled are alive or dead. For death, the researchers record the date and place. Death certificates are subsequently obtained through state health departments, and causes coded to a modification of the International Classification of Diseases. Whenever cancer is mentioned on a death certificate, additional confirmatory information is requested from doctors, hospitals, or registries, so that cause of death is based upon 'best available' evidence.

A total of 521555 men and 685748 women were initially enrolled. A small proportion of these were found to be ineligible (too young) or had contributed unusable questionnaires. This analysis is based upon responses from 508656 men and 676640 women.

In the first two years of this study, 11489 men and 7688 women were reported dead. Figure 1 shows the standardized mortality ratio (SMR) for all causes by relative weight, defined as subject's weight divided by average weight for all subjects of the same sex, age (5-year group), and height (to the inch). Both non-smokers and smokers exhibited a Ushaped curve, with highest death rates for the severely under- and overweight. All SMR's were statistically significant for current smokers $(p<0.001)$ and for nonsmokers $(p<0.01$ except for females with relative weight $80-89 \% p<0.05)$. Similar results were obtained with cancer deaths (Figure 2). The same pattern was seen for men and for women (Garfinkel \& Stellman, 1988). All SMR's were statistically significant for current smokers $(p<0.001$, except for females with relative weight $130 \%$ or more $p<0.05$ ). Among non-smokers significantly elevated SMR's were observed for both men $(p<0.05)$ and women $(p<0.001)$ with relative weight $130 \%$ or more, and for women with relative weight $105-119 \%(p<0.001)$.

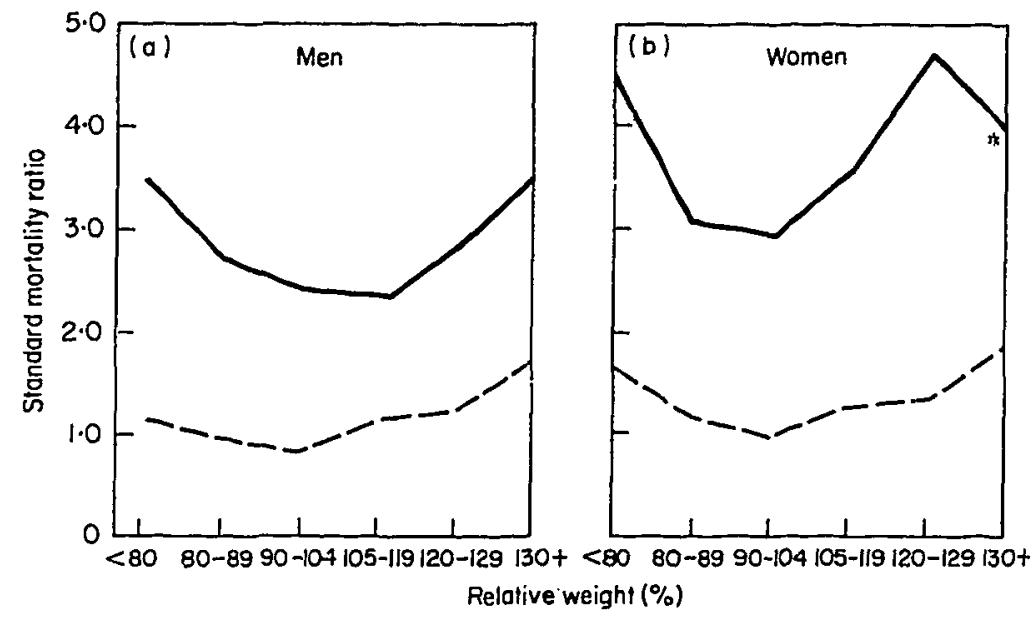

FIGURE 1. Standardized mortality ratios by relative weight, for all causes of death, for current smokers, - , and non-smokers, ---, in (a) men and (b) women. Non-smokers with relative weight $90-104=100$. *SMR based on only 12 deaths. 

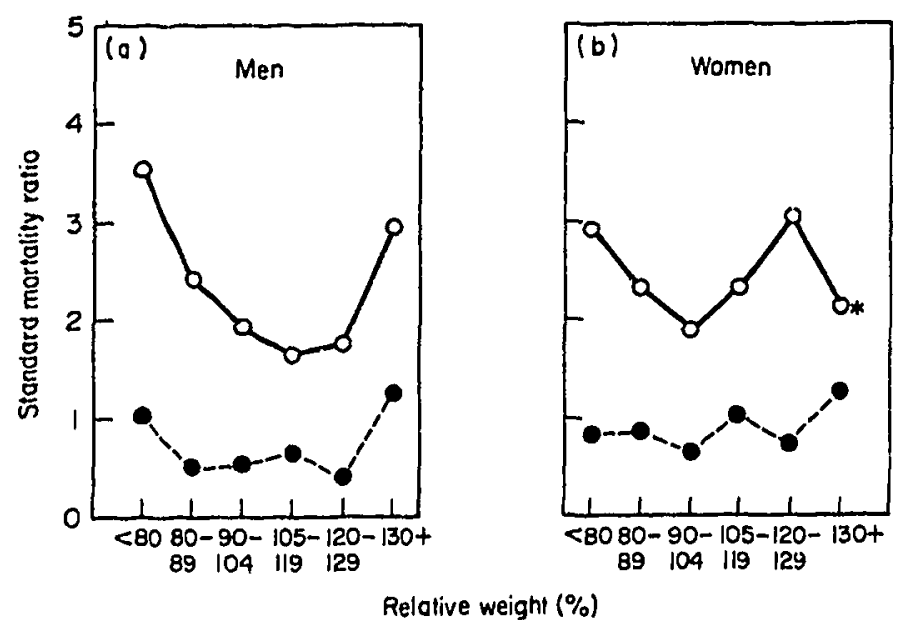

Figure 2. Standardized mortality ratios by relative weight for cancer (all sites), for current smokers, - , and non-smokers, -.., in (a) men and (b) women. Non-smokers with relative weight 90-104=10. *SMR based on only three deaths.

These findings suggest that weight control might be an important strategy in prevention of cancer and other chronic diseases. One strategy for weight control might involve use of artificial sweeteners (AS). The potential health hazards of artificial sweeteners have been investigated in considerable detail (Committee on the Evaluation of Cyclamate for Carcinogenicity, 1985; Wynder \& Stellman, $1980 a, b$ ), but their efficacy in a long-range weight control strategy has never been satisfactorily demonstrated (Committee for a Study on Saccharin and Food Safety Policy, 1978). Since use of AS is so widespread, we attempted to make use of available data within our very large cohort to test this possibility in a limited way. On the baseline questionnaire subjects were asked to provide their current weight, and their weight one year previously. We analysed this one-year weight change in relation to AS usage (Stellman \& Garfinkel, 1986 b).

Relative weight is correlated with a large number of lifestyle variables, many of which have the potential to introduce serious confounding (Stellman, 1987). We minimized the problem of confounding by restricting our analysis to subjects who were alike on the following variables: sex (all female), age (50-69 years), smoking (no change in preceding 5 years), education (at least high school), health (no history of diabetes, cancer, or heart disease), diet (no major change stated in past 10 years); and who were either current AS users of at least 10 years' duration or who had never used AS. All analyses were stratified by body mass index (BMI) and adjusted for age in 5-year intervals.

Out of 685748 women originally enrolled in the cohort, 78694 women met these restrictions. There were 17016 long-term AS users (21.6\%) and 61678 non-users. Obesity was positively correlated with AS usage: the overall proportion of AS users increased with BMI from $12.9 \%$ in the lowest quintile to $29.8 \%$ in the highest (Figure 3). Figure 4 shows the percentage of women who gained weight, lost it, or stayed the same over the 1981-1982 pre-enrolment period. The percent who gained weight was significantly higher among users than among non-users, at every level of initial BMI. Among those who gained weight, the average number of pounds gained by AS users was significantly higher (by 0.5 to $1.5 \mathrm{lb}$ ) than the amount gained by non-users. Among 


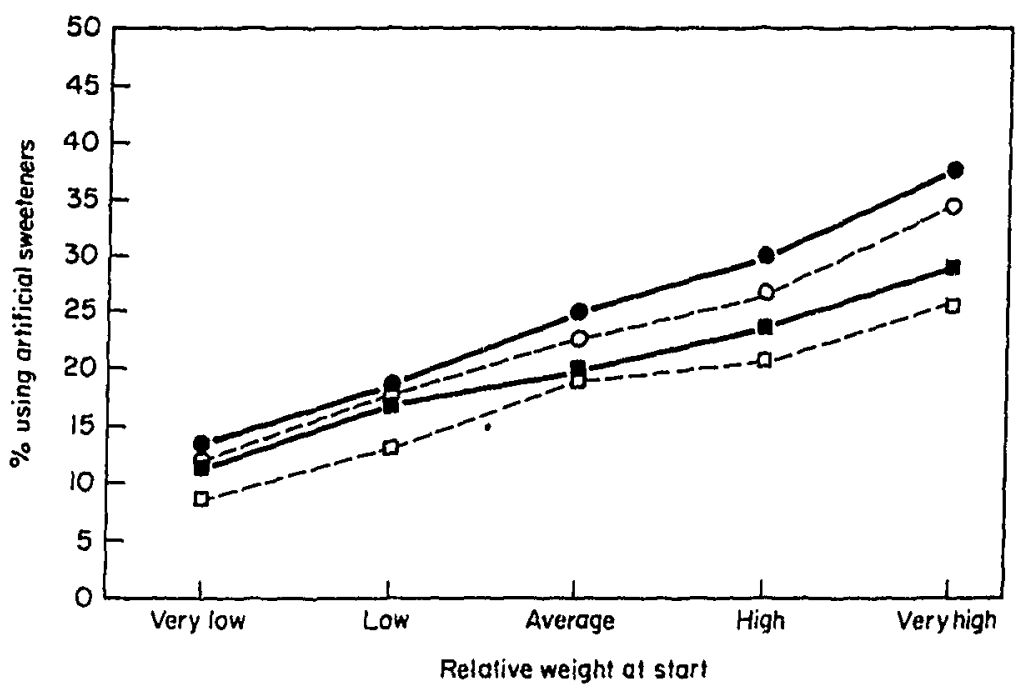

FIGURE 3. Variation of artificial sweetener use with age and relative weight among 78694 white women ages 50-69 years. All women had at least high school education, had no history of heart disease, cancer, or diabetes, and did not experience a major change in either diet or smoking habit during the preceding 10 years. Use of artificial sweeteners means current use of at least, 10 years' duration in any form, including tabletop sweeteners and diet beverages. $\bullet-, 50-54$ years; O--O, 55-59 years; $\square-\square, 60-64$ years; $\square--\square, 65-69$ years. Source: Stellman \& Garfinkel, $1986 b$ (reprinted by permission).

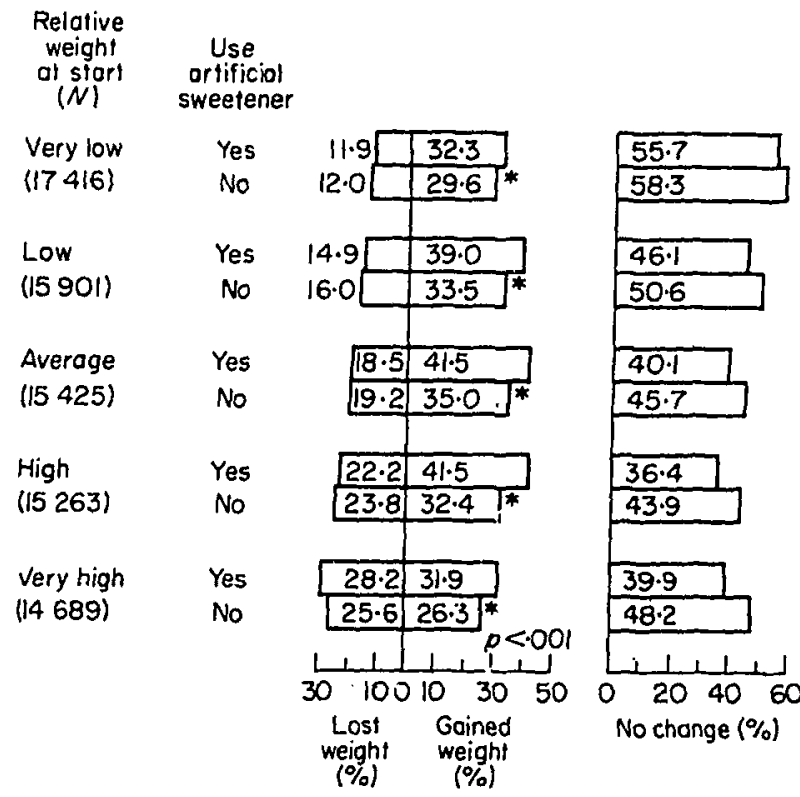

FIGURE 4. Percentage of women who gained or lost weight or whose weight did not change during the one-year period prior to enrolment in the study, according to artificial sweetener use. Percentages are adjusted for age in 5-year intervals. Source: Stellman \& Garfinkel, $1986 b$ (reprinted by permission). 
TABLE 1

Mean number of times per week specific foods were eaten classified by artificial sweetener $(A S)$ usage

\begin{tabular}{|c|c|c|c|c|}
\hline & \multicolumn{2}{|c|}{ Men } & \multicolumn{2}{|c|}{ Women } \\
\hline & No & Yes & No & Yes \\
\hline Beef & 2.8 & $2 \cdot 7^{*}$ & $2 \cdot 6$ & $2 \cdot 5^{*}$ \\
\hline Pork & 1.5 & $1.4 *$ & $1 \cdot 2$ & $1 \cdot 3^{*}$ \\
\hline Chicken & $1 \cdot 7$ & $1 \cdot 9 *$ & 1.9 & $2 \cdot 1^{*}$ \\
\hline Liver & 0.3 & 0.3 & 0.3 & 0.3 \\
\hline $\mathrm{Ham}$ & $1 \cdot 2$ & $1 \cdot 1^{*}$ & 0.9 & 0.9 \\
\hline Fish & 1.4 & $1.5^{*}$ & $1 \cdot 4$ & $1.7^{*}$ \\
\hline Smoked meats & 0.8 & 0.8 & 0.6 & 0.6 \\
\hline Frankfurters, sausage & 1.2 & 1.2 & 0.9 & $1.0^{*}$ \\
\hline Butter & $2 \cdot 7$ & $1.9^{*}$ & $2 \cdot 8$ & $1.9^{*}$ \\
\hline Margarine & $5 \cdot 1$ & 5.0 & $5 \cdot 2$ & 5.2 \\
\hline Cheese & $3 \cdot 1$ & $3 \cdot 1$ & $3 \cdot 4$ & $3 \cdot 5$ \\
\hline Eggs & $2 \cdot 9$ & 2.9 & $2 \cdot 7$ & $2 \cdot 8 *$ \\
\hline Green leafy vegetables & $4 \cdot 6$ & $4 \cdot 8^{*}$ & 4.9 & $5 \cdot 1^{*}$ \\
\hline Tomatoes & 3.5 & $3 \cdot 7^{*}$ & 3.7 & $3.9 *$ \\
\hline Cabbage & 1.8 & $2 \cdot 0^{*}$ & $2 \cdot 1$ & $2 \cdot 2^{*}$ \\
\hline Raw vegetables & $3 \cdot 3$ & $3 \cdot 4^{*}$ & $4 \cdot 2$ & $4 \cdot 4^{*}$ \\
\hline Carrots & $2 \cdot 0$ & $2 \cdot 1^{*}$ & $2 \cdot 3$ & $2 \cdot 4$ \\
\hline Squash & 1.7 & $1 \cdot 7$ & 1.8 & 1.8 \\
\hline Citrus fruits and juices & 4.8 & $4 \cdot 9^{*}$ & $5 \cdot 2$ & $5 \cdot 3$ \\
\hline Pasta & 1.8 & $1.7^{*}$ & 1.9 & $1.8^{*}$ \\
\hline White bread & 4.5 & $4 \cdot 0^{*}$ & $4 \cdot 1$ & 3.8* \\
\hline Brown rice or whole wheat & $2 \cdot 3$ & $2 \cdot 3$ & $2 \cdot 4$ & 2.5 \\
\hline Bran or corn muffins & 0.9 & $1 \cdot 0^{*}$ & 0.9 & $1 \cdot 0^{*}$ \\
\hline Potatoes & $3 \cdot 6$ & $3 \cdot 1^{*}$ & $3 \cdot 2$ & $2 \cdot 8^{*}$ \\
\hline Oatmeal or shredded wheat & $2 \cdot 6$ & $2 \cdot 8 *$ & $2 \cdot 6$ & $2 \cdot 7$ \\
\hline Cold cereals & $2 \cdot 8$ & $2 \cdot 9$ & $2 \cdot 4$ & $2 \cdot 5^{*}$ \\
\hline Ice cream & $2 \cdot 6$ & $2 \cdot 4 *$ & $2 \cdot 3$ & $2 \cdot 2^{*}$ \\
\hline Chocolate & $1 \cdot 7$ & $1 \cdot 5^{*}$ & 1.8 & $1 \cdot 7^{*}$ \\
\hline
\end{tabular}

Note: No, never used. Yes, current user.

$* p<0.05$.

those who lost weight, the number of pounds lost differed between users and non-users only in the obese; there, AS users lost 0.7 to $1.4 \mathrm{lb}$ more than did non-users. These last two comparisons were the only observations favorable to AS users in the entire study. These observed gains and losses, though statistically significant owing to the large sample size, probably have little clinical meaning (Stellman \& Garfinkel, 1986 b).

Perhaps AS users' weight change patterns are different because their food consumption patterns are different. We examined this possibility by tabulating the frequency of consumption of 28 food items in a subsample of 25000 men and 25000 women randomly selected from the cohort of 1.2 million subjects. Table 1 compares the average number of times per week that AS users and non-users reported eating these foods. AS users of both sexes ate chicken, fish, green leafy vegetables, tomatoes, cabbage and other raw vegetables significantly more often than did non-users, and ate beef, butter, pasta; white bread, potatoes, ice cream and chocolate significantly less often. The first group of foods would be generally deemed to have relatively high caloric 
TABLE 2

Food frequency results

\begin{tabular}{|c|c|c|}
\hline & Males & Females \\
\hline $\begin{array}{l}\text { Food items eaten } \\
\text { significantly less often by } \\
\text { AS users than by non- } \\
\text { users }\end{array}$ & $\begin{array}{l}\text { Becf, pork, ham, butter, } \\
\text { pasta, white bread, } \\
\text { potatoes, ice cream, } \\
\text { chocolate }\end{array}$ & $\begin{array}{l}\text { Beef, butter, pasta, white } \\
\text { bread, potatoes, ice } \\
\text { cream, chocolate }\end{array}$ \\
\hline $\begin{array}{l}\text { Food items eaten } \\
\text { significantly more often by } \\
\text { AS users than by non- } \\
\text { users }\end{array}$ & $\begin{array}{l}\text { Chicken, fish, green leafy' } \\
\text { vegetables, tomatoes, } \\
\text { cabbage, raw vegetables, } \\
\text { carrots, citrus fruits or } \\
\text { juices, bran or corn } \\
\text { muffins, oatmeal or } \\
\text { shredded wheat }\end{array}$ & $\begin{array}{l}\text { Pork, chicken, fish, } \\
\text { frankfurters, sausage, } \\
\text { eggs, green leafy } \\
\text { vegetables, tomatoes, } \\
\text { cabbage, raw vegetables, } \\
\text { bran or corn muffins, cold } \\
\text { cereal }\end{array}$ \\
\hline $\begin{array}{l}\text { Food items eaten equally } \\
\text { often by AS users and } \\
\text { non-users }\end{array}$ & $\begin{array}{l}\text { Liver, smoked meats, } \\
\text { frankfurters, sausage, } \\
\text { margarine, cheese, eggs, } \\
\text { squash, brown rice or } \\
\text { whole wheat, cold cereals }\end{array}$ & $\begin{array}{l}\text { Ham, liver, smoked meats, } \\
\text { margarine, cheese, } \\
\text { carrots, squash, citrus } \\
\text { fruits or juices, brown rice } \\
\text { or whole wheat, oatmeal } \\
\text { or shredded wheat }\end{array}$ \\
\hline
\end{tabular}

content. These food frequency results, which are summarized in Table 2, seem to suggest that AS users tended to gain weight in spite of an apparent preference for lowercaloric diets than those eaten by non-users. However, our observations do not include serving size and we therefore cannot estimate total food consumption, and especially total calories, nor can we test the hypothesis that AS users increased their total food consumption, thereby leading them to gain more weight than non-users. This provocative observation can be confirmed only through a carefully controlled clinical study using objective measures of caloric intake. We hope that other investigators will undertake such a study.

Since this is strictly an observational and not an experimental study, there are important limitations on our interpretation of results. It may be that AS users who lost weight or at least whose weight did not increase would otherwise have got fatter. This possibility can only be studied through a controlled trial. It may be that shortterm usage, alone or coupled with a major dietary change, is beneficial; we studied only long-term continuous usage. And of course we can make no inferences about the 607054 women who did not fulfill the highly selective conditions for inclusion. The most conservative conclusion is that casual long-term usage of AS in the absence of other major changes in lifestyle does not by itself lead to weight loss.

\section{REFERENCES}

Committee for a Study on Saccharin and Food Safety Policy (1978) Saccharin: technical assessment of risks and benefits, Report No. 1. Assembly of Life Sciences, Institute of Medicine, National Research Council, Washington, D.C.: National Academy of Sciences.

Committee on the Evaluation of Cyclamate for Carcinogenicity (1985) Evaluation of cyclamate for carcinogenicity. Commission on Life Sciences, National Research Council, Washington, D.C.: National Academy of Sciences. 
Garfinkel, L. \& Stellman, S. D. (1988) Mortality by relative weight and exercise. Cancer. In press.

Lew, E. A. \& Garfinkel, L. (1979) Variations in mortality by weight among 750,000 men and women. Journal of Chronic Diseases, 32, 563-576.

Stellman, S. D. (1987) Confounding. Preventive Medicine, 16, 165-182.

Stellman, S. D. \& Garfinkel, L. (1986 a) Smoking habits and tar levels in a new American Cancer Society prospective study of 1.2 million men and women. Journal of the National Cancer Institute, 76, 1057-1063.

Stellman, S. D. \& Garfinkel, L. (1986b) Artificial sweetener use and one-year weight change among women. Preventive Medicine, 15, 195-202.

Wynder, E. L. \& Stellman, S. D. (1980 a) Artificial sweetener use and bladder cancer: a casecontrol study. Science, 207, 1214-1216.

Wynder, E. L. \& Stellman, S. D. $(1980 b)$ Artificial sweetener use and bladder cancer: a case control study. Science, 210, 447-448. 